\title{
Retraction
}

\section{Retracted: Service Selection of Ensuring Transactional Reliability and QoS for Web Service Composition}

\author{
Mathematical Problems in Engineering \\ Received 10 November 2013; Accepted 10 November 2013; Published 22 January 2014 \\ Copyright (C) 2014 Mathematical Problems in Engineering. This is an open access article distributed under the Creative Commons \\ Attribution License, which permits unrestricted use, distribution, and reproduction in any medium, provided the original work is \\ properly cited.
}

The paper titled "Service Selection of Ensuring Transactional Reliability and QoS for Web Service Composition" [1], published in Mathematical Problems in Engineering, has been retracted as it is found to contain a substantial amount of material, without referencing, from the following published articles:

(i) Joyce El Haddad, Maude Manouvrier, Marta Rukoz: TQoS: Transactional and QoS-Aware Selection Algorithm for Automatic Web Service Composition. IEEE T. Services Computing 3(1): 73-85 (2010).

(ii) Joyce El Haddad, Maude Manouvrier, Guillermo Ramirez, Marta Rukoz: QoS-Driven Selection of Web Services for Transactional Composition. ICWS 2008: 653-660.

\section{References}

[1] G. Zhang, L. Chen, and W. Ha, "Service selection of ensuring transactional reliability and QoS for web service composition," Mathematical Problems in Engineering, vol. 2012, Article ID 641361, 15 pages, 2012. 